\title{
Protection against debris flows with 13 flexible barriers in the Milibach River (Canton Berne, Switzerland) and first event analysis
}

\author{
C. Wendeler \& B. Vjekoslav \\ Geobrugg AG, Switzerland
}

\begin{abstract}
The villages Hasliberg Reuti and Meiringen in Switzerland were affected by flood and debris flow events resulting from unusually large rainfall in August 2005. The endangerment of these settlements was not consistent with the existing damage potential and thus the need for action was very great. Due to the difficult natural basic conditions in the catchment area with permanent sliding of alénien schist material with very low friction coefficient if infiltrated by water, conventional preventive stiff measures could not be used there because of foundation problems. A promising new solution was selected with 13 flexible ringnet barriers providing a total retention capacity of $12,000 \mathrm{~m}^{3}$. Because of little experience with this new type of protection measure in dimensioning, wellfounded investigations with extensive laboratory tests and numerical simulations had to be undertaken. These analyses gave the maximal possible certainty to engineers and authorities that these measures will afford adequate protection and keep the residual risk as low as possible. Close co-operation between the scientific team of the WSL, the industrial partner and the cantonal authority during the dimensioning process led to a consistent and technically plausible solution.

On 10th October 2011, another big storm occurred in the Hasliberg area with a 100 year flood declared from the Federal Office for the Environment (FOEN). The rainfall in the Berner Alps summarized within 12 hours up to $80 \mathrm{~mm}$ plus the stored water by the snow fall of up to $70 \mathrm{~cm}$ resulted in flooding of mountain rivers, slope failures and landslides. Around $2,000 \mathrm{~m}^{3}$ of material were mobilized in the catchment area of Hasliberg by a shallow landslide flowing into the torrent. One of the 13 barriers was filled completely and two others were half filled. The new protection measure installed in 2008 predicts a bigger debris flow
\end{abstract}


event by already stopping the material in the catchment area and avoiding further erosion of the flow process river upstream which happened in August 2005.

Keywords: debris flow prevention, multilevel ringnet barriers, shallow landslides.

\section{Introduction}

The Milibach rises in the Gummen Region the water border of the Oberhasli to the Canton Obwalden. On its way down it flows through the eastern to the western part of the Hasliberg settlement and flows after a deep canyon into the Aare River. The local situation can be seen in Figure 1.

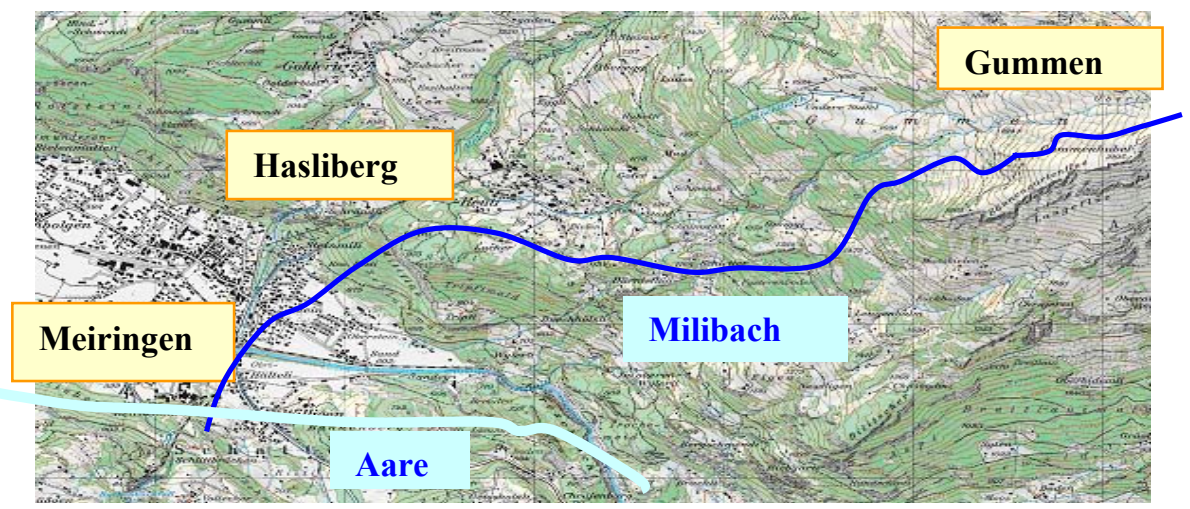

Figure 1: $\quad$ Situation of the Milibach, taken out of LK 1:25,000, Number 1209 Innertkirchen.

The valley of Gummen is made of slope parallel black clay rich alénien schist (Alénienschiefer). Sometimes there are some parts of sandstone in between. The slope parallel schist is very sensitive to weather and acts as an aquiclude [1].

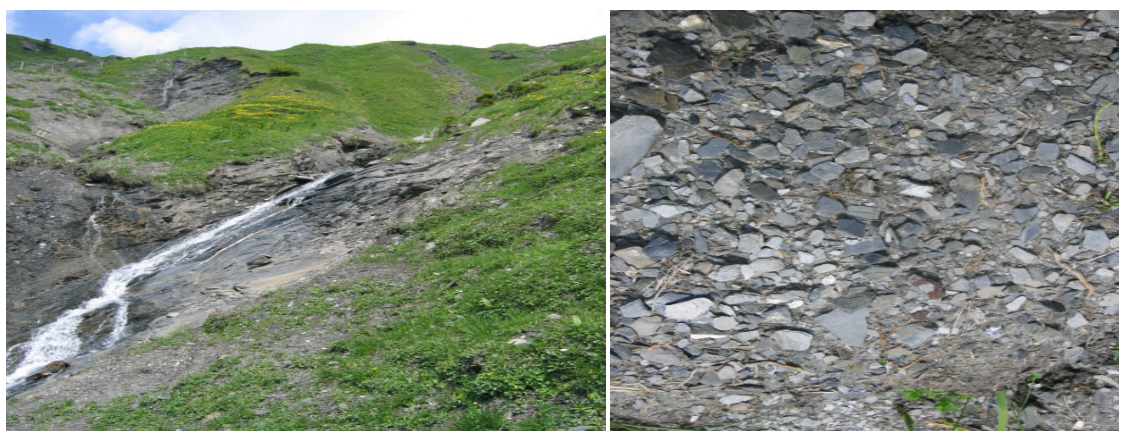

Figure 2: Catchment area with the Milibach in the Gummen region (left), alénien schist material (right). 
This formation is overlaid by a weathered, several meter thick debris layer. This layer forms the origin for the debris flow material and consists of the weathered part of the upper Doggers. Parts of moraines occur only infrequently within the debris.

The debris is a very clayey, silty and also sandy material with a lot of bigger stones and boulders. If the material is dry its internal friction angle $\varphi$ ' lies between $25-28^{\circ}$ with an apparent cohesion of $\mathrm{c}^{\prime}=0-3 \mathrm{kN} / \mathrm{m}^{2}$. If the material is saturated with water, these values rapidly get lower, even the internal friction angle reaches values of $15^{\circ}$. After wet periods with a lot of rainfall these packets of granular soil are mobilized as shallow landslides and transporting the debris into the river. Very particular is the low plasticity of the material. The part of clay and silt is $15-20 \%$. This fact is a very big problem for the disposal construction because they have to be built very flat with strong retaining walls [2].

\section{Event 2005}

In August 2005 during heavy rainfalls the settlements of Hasliberg Reuti and Meiringen were flooded. The debris flows initialised at the Gummen catchment area caused main disaster of human infrastructure (figure 3).

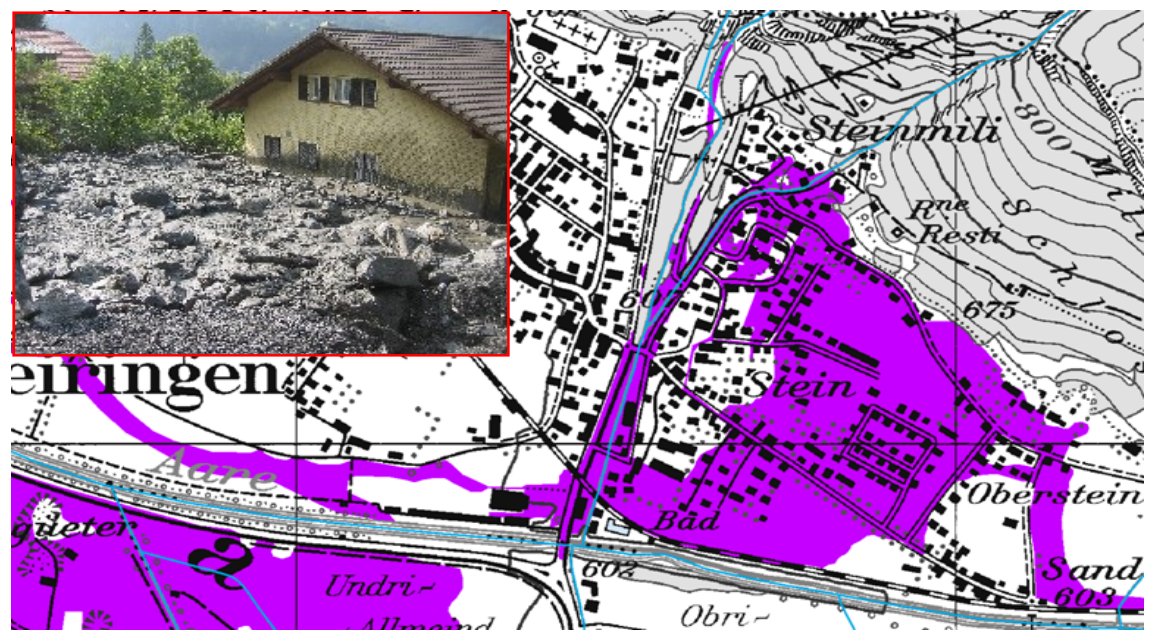

Figure 3: Deposited debris in the village of Meiringen (violet) caused major damage to infrastructure and houses.

Around $13,000 \mathrm{~m}^{3}$ of the weathered schist material in the catchment were mobilized during the intensive rainfall and were transported within 3 surges down the channel. Along its way down a further $25,000 \mathrm{~m}^{3}$ were picked up by erosion processes and expanded the total volume of the flow up to $40,000 \mathrm{~m}^{3}$. 
The flow velocities of this event could be determined very reliably to 7 up to $9 \mathrm{~m} / \mathrm{s}$ out of the superelevation. The velocities, flow heights and flow discharges can be recalculated as a turbulent Newton flow regime after Cheyz or Strickler.

The marginal shear stress could be approximated out of border deposition after the events to $600 / 1100 \mathrm{~N} / \mathrm{m}^{2}$ hence these debris flows were muddy. The water content of the flow was around $50 \%$. The density of the flow itself was in the range of $18-20 \mathrm{kN} / \mathrm{m}^{3}$ [2].

\section{Proposed protection measure with flexible ringnet barriers in the Gummen catchment area}

To avoid damage such as that in 2005 one measure of the complete protection concept of the village Hasliberg and Meiringen was to place 13 multilevel flexible barriers in the catchment area Gummen to stop the initial debris flows before developing the enormous erosion potential flowing down the channel and picking up more and more material. Flexible structures with nets seemed to be the best solution in this terrain because of the unstable alénien schist material which is permanently creeping and moving. Fix and stiff protection measures like concrete check dams would result in a lot of maintenance work because of cracks and eroded foundations.

The design parameter for the flexible ringnet barriers were reconstructed from the past event in 2005 and are shown in table 1 [3].

Table 1: $\quad$ Debris flow design values [6-8].

\begin{tabular}{|c|c|c|}
\hline Parameter & Design Value & Overloading case \\
\hline Channel inclination & $30 \%$ & - \\
\hline $\begin{array}{c}\text { Type of debris } \\
\text { flow }\end{array}$ & Mud flow, viscous flow & - \\
\hline Total volume & $10.000-15.000 \mathrm{~m}^{3}$ & - \\
\hline Surge volume & $5.000 \mathrm{~m}^{3}$ & $18-22 \mathrm{kN} / \mathrm{m}^{2}$ \\
\hline Flow bulk density & $18-20 \mathrm{kN} / \mathrm{m}^{2}$ & $100-150 \mathrm{~m}^{3} / \mathrm{s}$ \\
\hline Max. discharge & $60 \mathrm{~m}^{3} / \mathrm{s}$ & - \\
\hline Flow height & $1.5-2 \mathrm{~m}$ & up to $18 \mathrm{~m} / \mathrm{s}$ \\
\hline Flow velocity & $6-12 \mathrm{~m} / \mathrm{s}$ & \\
\hline
\end{tabular}

The dimensioning of the flexible ringnet barriers was carried out using the finite element software FARO [4]. Using the results of the test site Illgraben [5, 9] for validation, this software initially developed for rockfall simulations has 
been adapted to the debris flow load case. Compared to rockfall, debris flows are characterized by distributed loads instead of a punctual load, longer braking time, smaller deflection and several surges arriving onto the net.

For the dimensioning of the 13 ringnet barriers at the Gummen project, the following load cases have been considered:

viscous debris flows;

muddy debris flows;

static load for filled nets (active earth trust value);

snow load (gliding and impact of an avalanche);

overload case.

Barrier number 1 (first from the top) was calculated as a so-called "debris flow breaker". The highest intensity of debris flow pressure was simulated for this first barrier. In case of failure of the first barrier because of overloading, in fact the retained volume of this barrier will be lost but energy will be absorbed already of the debris flow front itself.

Barrier number 2 was additionally dimensioned to absorb the energy of an avalanche acting on the barrier with an impact angle of 10 degrees because an avalanche release zone is closed to the right river bank upstream. To avoid the full avalanche pressure onto the barrier, the barrier was not placed rectangular to the avalanche flow direction in the torrent. Furthermore, the simulation results for the applied snow load showed that for snow gliding, the forces in the cables do not reach the activation load of the brake elements thus they do not have to be especially secured in winter time [6].

Calculations showed that for the given heavy requirements, only ringnets with very high resistance may be used for this project. Therefore, the net components like the ringnet, ropes and brake rings used are the strongest elements available at the moment.

The performed cost sensitive analysis done by the Canton of Bern only focusing on the net protection without the other measures realized in whole protection concept showed that the annual costs to avoid a 100-year flood event should not be higher than 1.3 Mio CHF. With the ringnets and the complete maintenance concept for a life time span of 20 years the complete costs for the barriers are 177,000 CHF per year and so 7 times more cost effective. Additional remark, only with the protection nets the damages in the villages Hasliberg and Meiringen can be reduced for a 30-year debris flow event from 65 Mio CHF to 10 Mio CHF and for a 100-year event still from 69 Mio to 65 Mio CHF [5].

\section{Event 10th October 2011 Gummen Hasliberg}

The main problem leading to this flood was more than $70 \mathrm{~cm}$ of snow fall in the Berner Alps one day before the storm arrived. Next day another storm brought heavy rainfall to the Swiss Alps from a western direction (see figure 4). Until lunch time on Monday the rainfall in the Berner Alps summarized in the last 12 hours up to $80 \mathrm{~mm}$. The fresh water entry by rainfall plus the stored water by the snow fall resulted in flooding of mountain rivers, slope failures and landslides. In 
the Berner Alps the federal institution for environmental concerns BAFU declared this storm to a 100-year flood.

In the Gummen catchment area around 2,000 $\mathrm{m}^{3}$ of material got mobilized $10^{\text {th }}$ October, most of the material brought by a shallow landslide close to flexible ringnet barrier No 2 (see figure 5).
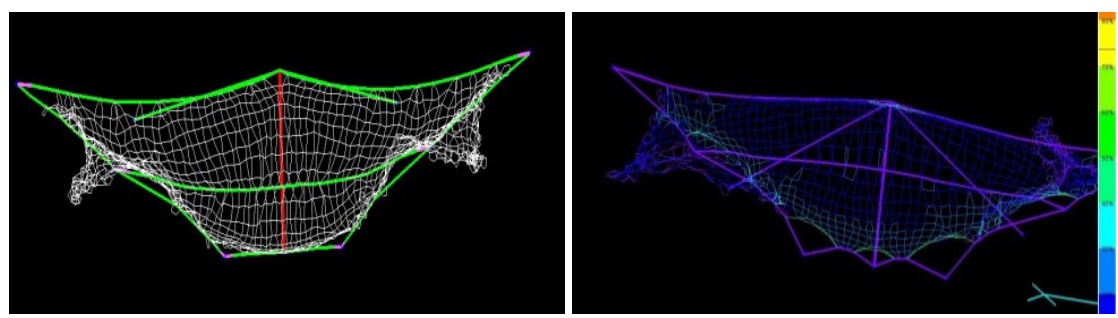

Figure 4: Simulation of representative barrier for project Gummen using the software FARO.

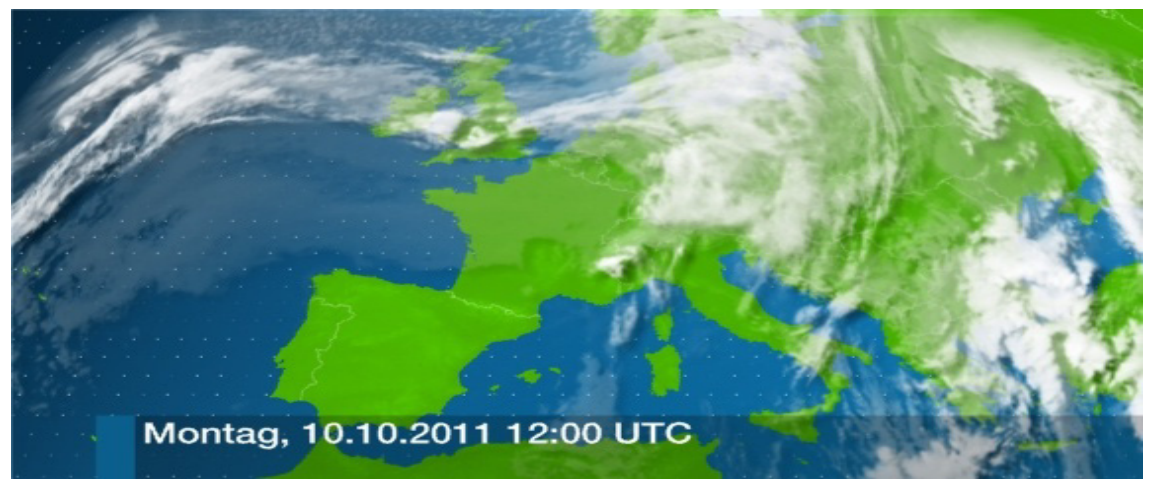

Figure 5: $\quad$ Satellite picture of storm 10th October crossing the northern Swiss Alps (source: SF meteo webpage).

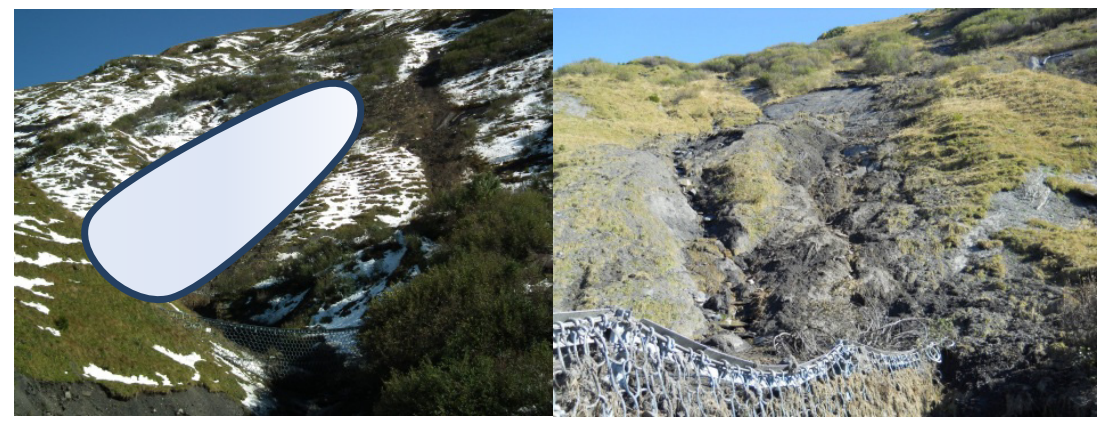

Figure 6: Shallow landslide close to flexible barrier No 2 caused the filling of this barrier. 
Flexible ringnet barrier No 2 got filled up to the max. level and flexible ringnet barrier No 5 filled up to half (see figure 6). The nets in between did not fill up because of their higher basal opening, the gap between the lower support rope and the river bed.

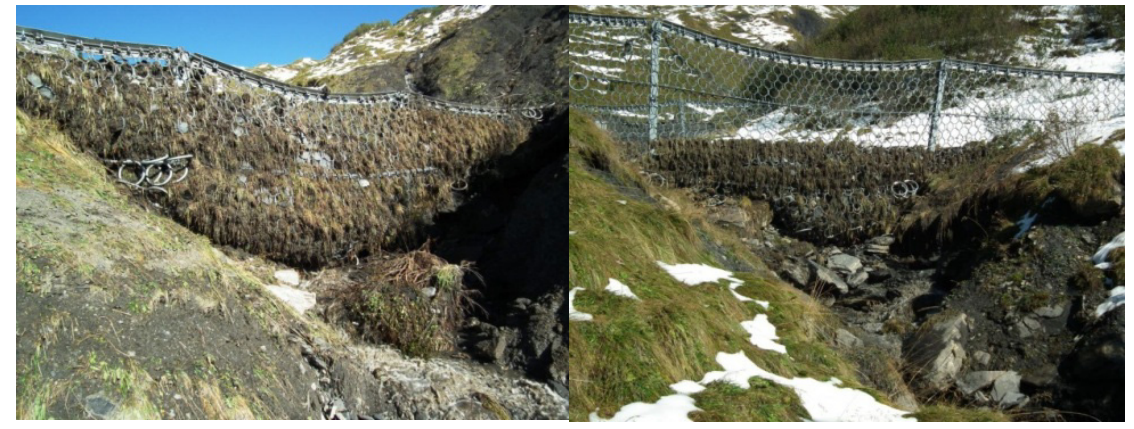

Figure 7: $\quad$ Stopped material behind barrier No 2 and barrier No 5 .

\section{Conclusion}

The customer, the two villages Hasliberg and Meiringen as well as the designer of this multi-level protection concept are satisfied with the function of the nets in the 2011 storm because without the barriers, the $2,000 \mathrm{~m}^{3}$ of the 100 -year flood would have eroded more material along the channel and could have caused much more damage again to Hasliberg village.

The customer as well as the project involved geologist decided to leave barrier No 2 filled in the torrent for the next time to stabilize the foot of the shallow landslide at the slope to the right view river upstream (see figure 5). Without the retention capacity of barrier No 2 the complete provided volume of the concept will be indeed reduced a bit but therefore the eroded slope can stabilize itself by nature grass covering. Barrier No 5 will be cleaned with normal water flow, some maintenance work will be required caused by eroded anchors at this barrier. But this aspect is hard to avoid in an event case in such a loose soil condition of alénien schist material which is easily eroded by water infiltration.

Also the complete developed design concept of the dimensioned barriers was proven by this event. No failure of the directly impacted barrier No 2 was happening even the shallow landslide brought a total volume of around $2000 \mathrm{~m}^{3}$ at once impacting the barrier. The material retained behind the barrier look dense with an estimated density of the slide of around $2,000 \mathrm{~kg} / \mathrm{m}^{3}$. To recalculate the impact forces of the slide to the barrier the velocity plays an important role. In that case for $30^{\circ}$ inclined slope it can be estimated to max. $10 \mathrm{~m} / \mathrm{s}$. Flow height of the slide are much harder to estimate and cannot be declared thus impact pressure acted on the barrier No 2 unluckily cannot be back calculated precisely. 


\section{References}

[1] Wenger, M. (2006): Zielsetzung, geologische Disposition, Schutzkonzept. B-I-G Büro für Ingenieurgeologie, Gümlingen. Vortrag anlässlich des Herbstkurses FAN Fachleute Naturgefahren Schweiz vom 21./22. September 2006 Meiringen.

[2] Wendeler, C., Volkwein, A., Roth, A., Herzog, B., Hählen, N., and Wenger, M., (2008): Hazard prevention using flexible multi-level debris flow barriers. In Proc. of Int. Symp. Interpraevent, dornbirn, Austria, Band 1, pp. 547-554.

[3] Herzog Ingenieure ETH/SIA (2006): Lokale lösungsorientierte Ereignisanalyse LLE Hasliberg/Meiringen. Bericht Laborversuche Murgangrückhalt Gummen, WSL, Wendeler, C., Birmensdorf, 11. August 2006.

[4] Volkwein A. (2005): Numerical Simulation of flexible rockfall protection systems, Proc. Computing in Civil Engineering. Cancun: ASCE.

[5] Wendeler C. (2008): Murgangrückhalt in Wildbächen - Grundlagen zu Planung und Berechnung von flexiblen Barrieren, Dissertation ETHZ, Zürich.

[6] Technischer Bericht und Bemessung, Milibach Meiringen, Murgangrückhalt Louwenenbach, Flexible Murgangrückhaltesysteme, Fatzer AG, Roth, A., Denk, M., Zünd, T., Romanshorn, August 2006.

[7] Gutachten "Milibach Meiringen, Murgangrückhalt Louwenenbach", Basler and Hofmann, Dr. M. Schatzmann, Zürich, 25. January 2006.

[8] Zimmermann, M., Geschiebeverhältnisse im Milibach. Thun 2005, Schweiz.

[9] McArdell, B. W., Wendeler, C., Roth, A., Kalejta, J., Rorem, E. (2007): Field observations of the interaction of debris flows with flexible barriers, First North American Landslide Conference, Vail. 